Fall 2017

\title{
Testing the Health Belief Model among African-American Gay/ Bisexual Men with Self-Efficacy and Minority-Specific Contextual Variables
}

\author{
Brian D. Zamboni \\ University of Michigan \\ Isiaah Crawford \\ University of Puget Sound \\ Fred B. Bryant \\ Loyola University Chicago, fbryant@luc.edu
}

Follow this and additional works at: https://ecommons.luc.edu/psychology_facpubs

Part of the Psychology Commons

\section{Recommended Citation}

Zamboni, Brian D.; Crawford, Isiaah; and Bryant, Fred B.. Testing the Health Belief Model among AfricanAmerican Gay/Bisexual Men with Self-Efficacy and Minority-Specific Contextual Variables. Journal of Black Sexuality and Relationships, 4, 2: 73-92, 2017. Retrieved from Loyola eCommons, Psychology: Faculty Publications and Other Works, http://dx.doi.org/10.1353/bsr.2017.0028

This Article is brought to you for free and open access by the Faculty Publications and Other Works by Department at Loyola eCommons. It has been accepted for inclusion in Psychology: Faculty Publications and Other Works by an authorized administrator of Loyola eCommons. For more information, please contact ecommons@luc.edu. (c) $(1) \Theta \Theta$

This work is licensed under a Creative Commons Attribution-Noncommercial-No Derivative Works 3.0 License. (c) 2018 James C. Wadley 


\title{
Testing the Health Belief Model among African-American Gay/Bisexual Men with Self-Efficacy and Minority-Specific Contextual Variables
}

\author{
BRIAN D. ZAMBONI, University of Minnesota \\ ISIAAH CRAWFORD, University of Puget Sound \\ FRED B. BRYANT, Loyola University Chicago
}

ABSTRACT - This study used structural equation modeling to test variations of the

Health Belief Model in predicting safer sex intentions among 151 African-American gay/bisexual men. Acculturation and gay socialization were included to see if minority-specific contextual variables improved the model fit. Perceived severity, perceived vulnerability, and cues to action did not improve the model. Including self-efficacy as a mediating variable improved the model and overall prediction of safer sex intentions. Although acculturation and gay socialization were not statistically significant additions to the model, there are conceptual and practical reasons why these variables may influence safer sex intentions among African-American gay/ bisexual men.

KEYwords-Health Belief Model, gay, African-American, HIV, condom, sex

Contact-Brian D. Zamboni, Ph.D., Program in Human Sexuality, University of Minnesota, 1300 S 2nd St., Ste. 18o, Minneapolis, MN, 55454; or by e-mail at bzamboni@umphysicians.umn.edu. 
He CENTERS FOR DISEASE CONTROL AND PREVENTION (CDC) HAS RE-
ported that African-American gay/bisexual men may be at high-
est risk for HIV infection compared to other racial/ethnic groups in the gay community (CDC, 2015). African-American gay/bisexual men are a marginalized population whose unique needs should be addressed, and more theory-based interventions for safer sex are needed with them (Hergenrather, Emmanuel, Durant, \& Rhodes, 2016). Theories and models of safer sex enable researchers to identify what specific constructs can be used to promote health behavior, and such models have been shown to be more effective than interventions without a theoretical base (Albarracin et al., 2005). African Americans may be less likely to identify as gay/bisexual because of biases within the African-American community against homosexuality, making them less likely to seek HIV preventive services (O'Leary et al., 2007). African-American gay/bisexual men experience the dual minority stressors of heterosexism and racism, putting them at risk for a variety of mental health challenges as well as sexually transmitted infections (Crawford, Allison, Zamboni, \& Soto, 2002; David \& Knight, 2008; Meyer, 2010). Collectively, this suggests that models of safer sex behavior should include contextual variables that are pertinent to African-American gay/bisexual men if health professionals are to help them maintain adequate psychological well-being and physical sexual health.

\section{The Health Belief Model}

The Health Belief Model (HBM; Rosenstock, 1974), a prominent theory of health behavior, posits that the intention to engage in HIV prevention behaviors result from a decision-making process in which individuals estimate their perceived risk for HIV, judge the severity of HIV, and evaluate the benefits and barriers to adopting the preventive behaviors. According to the HBM, cues to action (e.g., health messages) should start the process of thinking about disease susceptibility, disease severity, and benefits/barriers to behavior change (Rosenstock, 1974). The HBM has been shown to be useful in predicting safer sex behavior in samples of Caucasian gay men (Aspinwall, Kemeny, Taylor, Schneider, \& Dudley, 1991) and heterosexual African-American men (Aronson et al., 2013; Ford \& Norris, 1995).

Unfortunately, prior studies of the HBM have tested differences between groups or have used regression analyses to test the model. These techniques do not truly test the model as a whole because they do not permit a 
simultaneous test of multiple paths in the HBM. Structural equation modeling performs a simultaneous test of multiple paths and can identify superfluous aspects of the model that can be eliminated or new variables (e.g., cues to action) that can be added to enhance the overall model's predictive ability. Of the few studies that have used structural equation modeling to examine the HBM, some do not measure the entire HBM or have methodological flaws, such as unreliable instrumentation or using a single question to measure a construct (e.g., Brunswick \& Banaszak-Holl, 1996; Ford \& Norris, 1995; Neff \& Crawford, 1998). These studies did not examine ethnic minority gay/bisexual men. Moreover, research suggests that the ability of the HBM to predict safer sex behavior could be enhanced if other variables were added to the model, such as self-efficacy (Boone \& Lefkowitz, 2004; Khalil, Ross, Rabia, \& Hira, 2005).

\section{Self-Efficacy}

In another school of thought, social cognitive theory (e.g., Bandura, 1986) postulates that health protective behavior results from a judgment of selfefficacy (i.e., self-confidence), which involves an integration of knowledge about the disease, expected outcomes of engaging in the health protective behavior, and perceived social acceptance for the behaviors. Meta-analyses (Casey, Timmermann, Allen, Krahn, \& Turkiewicz, 2009; Lacefield, Negy, Schrader, \& Kuhlman, 2015; Sheeran, Abraham, \& Orbell, 1999) support the notion that self-efficacy is useful in predicting intention to use condoms and past condom use. Self-efficacy has been incorporated into a modified version of the HBM (Rosenstock, Strecher, \& Becker, 1988) as an exogenous independent variable, but some studies have suggested that self-efficacy is best viewed as a mediating variable (e.g., Wulfert \& Wan, 1993; Wulfert, Wan \& Backus, 1996). The latter model posits that self-efficacy mediates the relationship between perceived risk for HIV infection and safer sex behaviors (Wulfert \& Wan, 1993).

\section{Contextual Factors: Acculturation and Gay Socialization}

Theories of sexual health behavior need to account for the contextual factors associated with a minority community to identify pertinent determinants of sexual risk behaviors (e.g., Cochran \& Mays, 1993; Mays, Cochran, \& Zamudio, 2005). Acculturation is one such factor. Acculturation is defined 
as a change in cultural attitudes, values, and behaviors due to contact from two distinct cultures, and usually refers to the degree to which a minority culture adopts the majority (Cuellar, Nyberg, Maldonado, \& Roberts, 1997). Higher levels of acculturation have been associated with more positive condom attitudes, but unrelated to normative perceptions of condom use (San Doval et al., 1996). These mixed findings prevent any firm conclusions, but suggest that acculturation can be related to condom attitudes. Acculturation has often examined with Latino samples, possibly because African Americans are viewed as a racial/ethnic group without culture (Landrine \& Klonoff, 1994).

A contextual factor that has been applied to gay men is socialization into a sexual orientation subculture. Gay socialization refers to degree of coming out, degree of involvement in gay activities, and self-identification as a gay male (Vanable, McKirnan, \& Stokes, 1998). Seibt et al. (1995) found that higher levels of gay socialization and self-reported gay sexual identity were associated with higher levels of condom use during anal intercourse. Involvement with the gay/bisexual community may help men to have greater comfort with their sexuality and more social support for safer sex behaviors (Ratti, Bakeman, \& Peterson, 200o). Similar research with gay/bisexual Latino men has shown that greater involvement in the gay/bisexual community is associated with attitudes and behaviors supportive of safer sex practices (Agronick et al., 2004). Although an expanded version of the HBM has been examined by adding socialization (Boone \& Lefkowitz, 2004), this has not been done with African-American gay/bisexual men.

\section{Purpose and Hypotheses}

The purpose of the present study was to use structural equation modeling to investigate the HBM of sexual health behavior among African-American gay/bisexual men. Modified forms of the HBM were tested by adding cues to action, acculturation, and gay socialization. Self-efficacy was examined in the HBM both as an exogenous predictor and as a mediating variable. The endogenous dependent variable was intention to practice safer sex. Meta-analyses have shown that intentions predict safer sex behavior (e.g., Albarracin, Johnson, Fishbein, \& Muellerleile, 2001).

To examine the HBM in its most basic form, the model was configured as having four exogenous predictors of intentions to use condoms and engage in other safer sex practices. Fewer perceived barriers to and high- 
er perceived benefits of condom use, perceived vulnerability to HIV, and perceived seriousness of HIV infection were hypothesized to predict greater safer sex intentions. This model was hypothesized to fit the data at least moderately well.

In expanded forms of the HBM, cues to action, acculturation, and gay socialization were first specified as exogenous variables predicting the basic components of the HBM (Rosenstock, 1974). Higher levels of cues to action were theorized to predict higher perceived vulnerability and severity (Rosenstock, 1974). Higher levels of acculturation and gay socialization were hypothesized to predict fewer perceived barriers, higher perceived benefits, perceived vulnerability, and severity. When measures of cues to action, acculturation, and gay socialization were added to model (separately), the fit with the data was hypothesized to improve.

When self-efficacy was added as a mediator to the HBM in its basic form, model fit was hypothesized to improve. Thus, self-efficacy was tested of the indirect effects of the perception dimensions on intention to practice safer sex. Per this hypothesis, higher perceived benefits, vulnerability, and severity and fewer barriers would predict higher levels of self-efficacy, which, in turn, would predict greater safer sex intentions.

\section{Method}

\section{Participants}

Participants were 151 African-American gay/bisexual men aged 18 years or older. The sample primarily consisted of adults (mean age $=36.77$ years) who were single (47.7\%) and labeled their sexual orientation as "gay" (72.8\%). The sample's yearly income was positively skewed, with approximately $55 \%$ of the sample reporting $\$ 20,000$ or less. Those with a prior sexually transmitted disease (STD) other than HIV (52.3\%) had contracted gonorrhea (15.2\%), syphilis (7.9\%) or multiple STDs (11.9\%). Most had been tested for HIV (96\%) and $45.7 \%$ indicated they were HIV positive. Concerning current drug use, $57 \%$ used alcohol and $49 \%$ used tobacco. Few reported other drug use, but marijuana (36.4\%) was the most common. Past drug use was common, most notably marijuana $(76.2 \%)$ and cocaine $(55.6 \%)$.

\section{Procedure}

The data from this study were taken from a larger project investigating the sexual health behaviors of African-American gay/bisexual men. The study 
was approved by a university IRB, and an informed consent procedure was followed. Participants were recruited in a large, Midwestern city (USA) through print advertisements in weekly newspapers, outreach by recruiters in community settings (e.g., cafes or coffeeshops, street fairs, parks, bars), and snowball sampling techniques (i.e., referrals from men who participated in the study). Prior studies sponsored by the National Institutes of Health and the Centers for Disease Control and Prevention have successfully used these methods (e.g., Stokes, Vanable, \& McKirnan, 1996).

Print advertisements and field workers invited men to call a local university about a confidential study concerning the attitudes toward condoms and safer sex practices of "African-American men who have sex with men." The advertisement stated that the study would last about 60 minutes and that volunteers would be paid $\$ 20$. Men who called were screened for eligibility (i.e., they had to be 18 years or older, identify as engaging in sexual activity with other men, have completed at least 8 years of formal education, and be in fair or good medical condition). Individuals who met these criteria were given an appointment at the local university. Participants were greeted by a research assistant and escorted to a testing room. They were told that all information gathered for the study would be held in strict confidence and that they could discontinue participation at any time. The research assistant checked each survey for completion. The measures were presented in a counter-balanced order. Each participant received a written debriefing form.

\section{Measures}

Participants completed a demographic form in which they provided information regarding age, sex, relationship status, race/ethnicity, education level, religious affiliation, frequency of attending religious services, sexual orientation, history of STDs, HIV-antibody testing history and status, and drug use. Next, they completed the following scales:

The shortened, Form X-1 of the Marlowe-Crowne Social Desirability Scale (MCSDS; Strahan \& Gerbasi, 1972) was used as a measure of the tendency of participants to give socially desirable responses. The Form X-1 version correlates well with the full MCSDS and has adequate internal consistency reliability (e.g., Strahan \& Gerbasi, 1972; KR-20 = .88). In the current study, this 10-item scale had a KR-20 $=.78$.

The Perceived Severity of AIDS subscale from the AIDS Health Belief Scale (Zagumny \& Brady, 1998) was used to assess perceived severity of 
AIDS. This measure asks respondents to indicate their level of agreement with four statements about the severity of AIDS. Higher scores indicate greater degree of perceived AIDS severity. This subscale shows acceptable internal reliability (Cronbach's alpha $=.83$; Zagumny \& Brady, 1998). In the current study, this 4-item scale had a Cronbach's alpha $=.71$.

The Perceived Risk subscale from the Condom Attitude Scale (CAS; Sacco, Levine, Reed, \& Thompson, 1991) was used. Respondents indicate their level of agreement with statements about perceived AIDS risk. This CAS subscale was derived via factor analysis and has shown adequate reliability (Cronbach's alpha $=.73$ to .90 ) and validity. In this study, the 6item CAS had a Cronbach's alpha $=.73$.

A measure of cues to action was adapted from two sources because conceptually and psychometrically sound scales of this construct are lacking. Participants indicated if they personally knew people who are HIV-positive, have AIDS, or who died of AIDS (e.g., Bakker et al., 1997). Items were also adapted from Mahoney's (1995) Cues to Condom Action Scales. A confirmatory factor analysis supported the unidimensional structure of this measure. In the current study, this 15-item scale had a Cronbach's alpha $=.82$.

The Multidimensional Condom Attitudes Scale (MCAS; HelwegLarsen \& Collins, 1994) was used to assess perceived benefits and barriers to condom use. The 25-item MCAS contains five subscales: ReliabilityEffectiveness, Pleasure, Identity Stigma, Embarrassment about Negotiation and Use, and Embarrassment about Purchase. Respondents indicate their level of agreement with statements regarding aspects of condom use. The subscales were validated via factor analyses and all show good internal reliability across several studies (Cronbach's alpha $=.71$ to .94 ; HelwegLarsen \& Collins, 1994). In this study, Cronbach's alpha $=.82$.

The MCAS does not adequately address partner reactions as perceived benefits/barriers to condom use. Thus, the Partner Barriers subscale from the Condom Barriers Scale (PB-CBS; St. Lawrence et al., 1999; Cronbach's alpha $=.86$ to .90$)$ was used as an additional scale to assess perceived benefits/barriers. This 8 -item scale had a Cronbach's alpha $=.90$ for this study.

The Intention subscale from the Sexual Risks Scale (DeHart \& Birkimer, 1997) was used to measure intention to try to practice safer sex. Participants indicated to what degree 7 items were self-descriptive. This measure has acceptable internal reliability (Cronbach's alpha $=.86$ ) and construct validity (DeHart \& Birkimer, 1997). In this study, Cronbach's alpha $=.78$.

The Condom Use Self-Efficacy Scale (CUSES; Brien, Thombs, Mahoney, 
\& Wallnau, 1994) was used to assess people's perceived ability to use condoms in a variety of situations. Participants indicated their level of agreement with 28 statements. The CUSES showed good internal consistency in the current study (Cronbach's alpha $=.93$ ).

The Multigroup Ethnic Identity Measure (MEIM; Phinney, 1992) was employed to assess ethnic identity and acculturation, two closely related constructs that provide a fuller picture of one's cultural orientation. Higher scores reflect greater levels of ethnic identity (i.e., greater acculturation into the African-American community). The 14-item MEIM showed good reliability in the current study (Cronbach's alpha $=.87$ ).

The Identification and Involvement with the Gay Community Scale (Vanable et al., 1998) was used to assess perceived closeness with the gay community and involvement in gay-related social activities (e.g., reading a gay-oriented paper). This scale has shown adequate reliability (Cronbach's alpha $=.78$; test-retest $=.74$ ), and reasonable construct validity (Vanable et al., 1998). In the current study, this 8 -item scale had a Cronbach's alpha $=.75$.

\section{SEM Specification of the HBM Tests}

The first analysis of the HBM tested the basic model, in which four exogenous variables (perceived benefits to condom use, partner barriers to condom use, perceived severity of AIDS, and perceived vulnerability to HIV infection) predicted safer sex intentions, which in turn predicted a measure of condom use (i.e., lifetime frequency of condom use in vaginal and anal sex). The four exogenous variables were not allowed to intercorrelate in the path analysis. They were hypothesized to independently influence safer sex intentions. (Allowing the exogenous predictors to intercorrelate did not alter the substantive results.)

The next tests of the HBM involved examining the cues to action variable via the procedures outlined by Kline (1998, pp. 132-137). First, the entire model was tested, freeing each path coefficient for cues to action to the perceived severity and vulnerability endogenous variables. Second, the model was re-estimated, fixing to zero the path between the cues to action variable and the perceived severity variable. Because the second model is nested within the first, the goodness-of-fit chi-square values of the two models can be contrasted to obtain a difference chi-square ( $w i t h \mathrm{df}=1$ ), which is used to test the hypothesis that estimating the path coefficient from cues to action to the perceived severity variable improves model fit. The utility of adding 
acculturation and gay socialization to the HBM was examined using these same procedures.

\section{Results}

An alpha level of .o1 was selected as the criterion for statistical significance to reduce Type I error, given the large number of parameters being estimated. The scales showed adequate internal reliability. Social desirability was not significantly associated with the measures.

Path analyses were conducted via structural equation modeling using LISREL with the covariance matrix of measured variables as input (Joreskog \& Sorbom, 1996). Path analysis assumes that the measured variables have no measurement error (Kline, 1998). This drawback can be addressed via a sensitivity analysis, which involves conducting a path analysis, specifying the estimated error terms for each indicator, and examining the impact on path coefficients in the model (Kline, 1998). Although some correlations could exist between some related independent variables, the models were being conceptualized as a group of characteristics and skills that develop independently and influence safer sex behaviors.

Three indices were used to gauge model fit (Joreskog \& Sorbom, 1996): the goodness of fit index (GFI); the comparative fit index (CFI); and the incremental fit index (IFI). The GFI reflects how well the overall variancecovariance matrix explains the measured variables. The CFI and IFI indicate how much better the given model fits the data relative to a null model in which sampling error alone is assumed to explain the observed interrelationships (Tanaka, 1993). All three indices can range from zero to one. Fit indices above .90 are viewed as a minimum satisfactory level of model fit (see Kline, 1998).

\section{Testing the Basic Health Belief Model}

In the basic test of the HBM, the path coefficients were all in the expected direction: higher perceived benefits of condom use, perceived vulnerability to HIV infection, and perceived severity of AIDS predicted higher levels of safer sex intentions. Lower levels of partner barriers predicted higher safer sex intentions. The standardized path coefficients for perceived benefits $(\beta=.28, \mathrm{~d}=.40, p<.01)$ and partner barriers $(\beta=-.17, \mathrm{~d}=.19, p<.01)$ were significant at the .01 level, but the path coefficient for perceived severity of AIDS 
showed a statistical trend $(\beta=.07, \mathrm{~d}=.19, p<.05)$. The coefficient for perceived vulnerability was not significant $(\beta=.08, \mathrm{~d}=.17, p=.068)$. Model fit statistics are displayed in Table 1 . The model fit was perfect, indicating that the model perfectly reproduced the observed covariance matrix.

\section{Testing the Health Belief Model with Cues to Action}

Does including cues to action add to the HBM? Higher cues to action predicted higher perceived vulnerability $(\beta=.06, p>.05)$, but lower perceived severity of AIDS $(\beta=-.16, p>.05)$. The path coefficients were not significant, and the negative beta-weight likely reflects a spurious finding. (This pattern was also evident in later tests with acculturation and gay socialization paths to vulnerability and severity and, thus, will not be reiterated.) The other path coefficients matched the pattern from the prior test of the HBM. The fit of this model was poor (see Table 1).

The modification indices (i.e., estimated value of each fixed model parameter if freed) supported the assumption that cues to action did not have a direct relationship with safer sex intentions. Because of this and the nonsignificant path coefficients associated with cues to action, the difference in chi-square tests were not conducted.

\section{Testing the Health Belief Model with Acculturation and Gay Socialization}

Do contextual variables like acculturation and gay socialization add to the HBM? Higher levels of acculturation significantly predicted higher perceived benefits to condom use $(\beta=.25, \mathrm{~d}=.32, p<.01)$, but showed statistical trends in predicting higher perceived vulnerability to HIV $(\beta=.24, d=.22$, $p<.05)$ and lower levels of partner barriers $(\beta=-.21, d=.22, p<.05)$. The modification indices revealed that acculturation did not have a direct relationship with safer sex intentions. The overall fit of this model was relatively poor (see Table 1).

Difference of chi-square tests were performed to examine whether or not adding the acculturation variable improved the model fit. The model was run without the nonsignificant perceived severity path coefficient, and this model served as baseline model for the $\chi^{2}$ difference test (see Table 1). Estimating the acculturation to partner barriers path and acculturation to perceived vulnerability path narrowly missed showing statistical trends. In contrast, estimating the acculturation to perceived benefits path improved the model fit at the .o1 level (see Table 1). 
Table 1. Fit Indices for Model Tests and Change in Chi-square for Nested Models

\begin{tabular}{|c|c|c|c|c|c|c|c|}
\hline Model & $\chi^{2}$ & $d f$ & $\Delta \chi^{2}$ & GFI & CFI & IFI & $R^{2}$ \\
\hline 1. The basic HBM & 0.00 & 6 & - & 1.0 & 1.0 & 1.0 & .51 \\
\hline 2. HBM with cues to action & 45.71 & 9 & - & .91 & .47 & .51 & .51 \\
\hline HBM with a3. cculturation & 42.04 & 7 & - & .92 & .55 & .59 & .52 \\
\hline Model without severity path & 44.29 & 8 & - & - & - & - & - \\
\hline $\begin{array}{l}\text { partner barriers path fixed } \\
\text { at zero }\end{array}$ & 47.84 & 9 & 3.55 & - & - & - & - \\
\hline vulnerability path fixed at zero & 47.96 & 9 & 3.67 & - & - & - & - \\
\hline $\begin{array}{l}\text { perceived benefits path fixed } \\
\text { at zero }\end{array}$ & 51.70 & 9 & $7.41^{*}$ & - & - & - & - \\
\hline 4. HBM with gay socialization & 42.00 & 7 & - & .92 & .53 & .58 & .51 \\
\hline $\begin{array}{l}\text { model without severity, } \\
\text { vulnerability paths }\end{array}$ & $45 \cdot 36$ & 9 & - & - & - & - & - \\
\hline $\begin{array}{l}\text { partner barriers path fixed } \\
\text { at zero }\end{array}$ & 49.70 & 10 & $4.34^{+}$ & - & - & - & - \\
\hline $\begin{array}{l}\text { perceived benefits path fixed } \\
\text { at zero }\end{array}$ & 50.42 & 10 & $5.06^{+}$ & - & - & - & - \\
\hline 5. HBM with Self-Efficacy & 0.00 & 10 & - & 1.0 & 1.0 & 1.0 & .59 \\
\hline $\begin{array}{l}\text { 6. HBM with Self-Efficacy } \\
\text { as a mediator }\end{array}$ & 0.00 & 6 & - & 1.0 & 1.0 & 1.0 & .59 \\
\hline 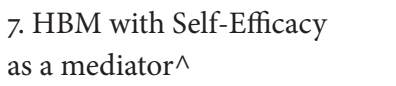 & 2.77 & 10 & - & .99 & 1.0 & 1.0 & .59 \\
\hline
\end{tabular}

Note: $\mathrm{HBM}=$ Health Belief Model. For each change in $\chi^{2}$ entry, degrees of freedom $=1$. The $\mathrm{R}^{2}$ represents the proportion of variance that the path model explained in safer sex intentions, the dependent variable. Blank entries denote instances in which the particular statistic was either inapplicable or irrelevant. The $\wedge$ denotes that this is a trimmed model.

Higher levels of gay socialization predicted higher perceived benefits of condom use $(\beta=.18, d=.26, p<.012)$, higher perceived vulnerability to HIV infection, and lower levels of partner barriers to condom use $(\beta=-.20, d=.24$, $p<.018)$. The path with perceived vulnerability was not statistically significant. The modification indices suggest that gay socialization does not have a direct relationship with safer sex intentions. The fit of this model was poor (see Table 1).

The $\chi^{2}$ difference tests were performed to examine whether or not adding the gay socialization paths improved the HBM. A model without the 
nonsignificant perceived severity and vulnerability paths served as the baseline model (see Table 1). The gay socialization to partner barriers path and the gay socialization to perceived benefits path each improved the model fit when estimated, but only a statistical trend for significance was evident $(p<.05)$.

\section{Testing the Health Belief Model with Self Efficacy}

To clarify the role of self-efficacy in the HBM, the basic HBM was tested with self-efficacy, partner barriers, and the perceived benefits, severity and vulnerability dimensions as independent predictors of safer sex intentions. Although the model fit was perfect (see Table 1), only the path between selfefficacy and safer sex intentions was statistically significant.

Self-efficacy was next tested as a mediator between the four independent variables and safer sex intentions. The four independent variables were allowed to predict both self-efficacy and safer sex intentions (i.e., two path coefficients were estimated for each independent variable). Two of the path coefficients for the direct effects on self-efficacy were significant. Higher levels of perceived benefits predicted higher levels of self efficacy $(\beta=.45$, $\mathrm{d}=.6 \mathrm{o}, p<.01)$ and lower levels of partner barriers predicted higher levels of self efficacy $(\beta=-.18, \mathrm{~d}=.44, p<.01)$. All four path coefficients for the direct effects on safer sex intentions were in the hypothesized direction, but only one path approached statistical significance. Higher levels of perceived severity of AIDS predicted higher safer sex intentions $(\beta=.07, \mathrm{~d}=.22, p<.05)$. Finally, higher levels of self-efficacy predicted higher safer sex intentions $(\beta=.57, d=.60, p<.01)$.

The previously significant direct effects of perceived benefits and partner barriers on safer sex intentions were not significant in this model. The paths between perceived benefits and self efficacy, perceived barriers and self efficacy, and self efficacy and safer sex intentions were all significant. This pattern of results supports the notion that self efficacy functions as a mediator in the model (Holmbeck, 1997). As a final check of the mediation, the path from perceived benefits to safer sex intentions was constrained to zero. The difference in $\chi^{2}$ between the two models $\left(\Delta \chi^{2}=.12\right)$ was not significant ( $p>$.01), indicating the direct path did not add to the model and supporting the mediational effect (Holmbeck, 1997). Self efficacy mediates the relationship between perceived benefits and safer sex intentions. The same procedures were used to support the finding that self efficacy mediates the relationship between partner barriers and safer sex intentions $\left(\Delta \chi^{2}=1.2, p>.01\right)$. 
The model was trimmed such that direct paths to safer sex intentions were fixed at zero for perceived benefits, partner barriers, or perceived vulnerability (see Figure 1). This more parsimonious model explained most of the variance-covariance in the measured variables $(\mathrm{GFI}=.99)$, and fit better than a null model (see Table 1).

\section{Discussion}

The basic tenants of the HBM were modestly supported as a framework for predicting safer sex among African-American gay/bisexual men: perceived benefits/barriers to safer sex behavior, perceived severity of AIDS, and perceived vulnerability appear to predict safer sex intentions for this group. The perceived benefits/barriers dimension, as measured by two instruments in this study, was clearly a strong predictor of safer sex intentions compared to the perceived vulnerability and severity components. The specific positive and negative consequences of engaging in safer sex behavior appear to exert a powerful influence on a person's intentions to practice safer sex. This finding is consistent with previous research on the benefits/barriers dimension of the HBM (e.g., Bakker et al., 1997; Carpenter, 2010). These appear to be the strongest components of the original HBM, which can be used to promote sexual health behavior with African-American gay/bisexual men.

Although the overall model fit appeared to be robust, the perceived severity of AIDS and perceived vulnerability paths did not add significantly to the model. Statistical fit indices for a model may be strong, but the same model can contain components that poorly fit the data or components that are not theoretically meaningful (Kline, 1998). These results correspond with prior research showing that the severity and vulnerability variables do not consistently predict safer sex intentions (Flowers, Sheeran, Beail, \& Smith, 1997; Gerrard, Gibbons, \& Bushman, 1996; Sheeran et al., 1999; Strecher, Champion, \& Rosenstock, 1997). Compared to perceived vulnerability, perceived severity of AIDS appeared to be a stronger predictor. Although these findings could reflect weak psychometric properties in the measures or an imperfect theory of safer sex behavior, a more likely explanation involves their theoretical versus practical significance in predicting safer sex practices. Perceived severity of AIDS and perceived vulnerability theoretically should predict safer sex behavior, but any actual influence of these two variables on safer sex practices may be too far removed from the safer sex behavior itself for researchers to measure statistically. African- 
American gay/bisexual men may consider their perceived vulnerability to HIV infection, but the perceived benefits/barriers to safer sex may determine their safer sex intentions because of its immediate effect on the sexual interaction. This may also explain the failure of cues to action to contribute to the HBM (Bakker et al., 1997; Flowers et al., 1997; Mahoney, 1995; Strecher et al., 1997). Individuals may explain their safer sex practices in part by citing public health messages and friends who have been affected by HIV, but these same individuals may be more influenced by the perceived benefits and barriers to safer sex behaviors. The implication of these results suggests that a modest amount of time in safer sex campaigns should be devoted to perceived severity of AIDS and perceived vulnerability, leaving more time for African-American gay/bisexual men to navigate the perceived benefits/barriers to safer sex.

\section{Expanding the Health Belief Model for}

African-American Gay/Bisexual Men

Some of the path coefficients involving acculturation and gay socialization, particularly with the partner barriers and perceived benefits/barriers dimensions, were in the hypothesized direction and marginally significant. These findings suggest that acculturation and gay socialization may have some influence on safer sex intentions for African-American gay/bisexual men. Yet, adding acculturation and gay socialization did not appear to improve the Health Belief Model. The findings of this study are similar to results from prior research showing that acculturation and gay socialization can predict safer sex attitudes and practices, but the relationships between these constructs are not consistently significant statistically (see Ratti et al., 2000). It is unlikely that the study lacked statistical power because only small models were tested. Although acculturation and gay socialization may be more important to the overall identity structure of AfricanAmerican gay/bisexual men (Crawford et al., 2002) and not their sexual practices, the results contradict this idea and it seems untenable to believe that one's socialization has no relationship with one's attitudes toward safer sex practices. Still, as with cues to action, any actual influence of acculturation and gay socialization on safer sex variables may be too distal for researchers to detect statistically. Knowledge about safer sex has been a poor predictor of safer sex intentions (e.g., Lewis, Malow, \& Ireland, 1997), but no intervention for HIV prevention would be complete without ensuring that basic education on safer sex is provided. Thus, acculturation and gay social- 
ization may still be important components in promoting safer sex behavior among African-American gay/bisexual men.

In addition, the models in this study may have been under-specified. Acculturation and gay socialization relate to social norm perceptions of safer sex. Acculturation and gay socialization may fit into a model of HIV prevention for African-American gay/bisexual men, but only when social norms are included in the model. This study may have excluded other important variables for African-American men that affect their safer sex practices, such as coping strategies and minority stress or experiences of racism.

Including self efficacy in the HBM clearly improved the model's explanatory power by incorporating a theoretically relevant variable into a model that is arguably overly parsimonious. A person's self-confidence concerning condom use clearly plays an important role in determining safer sex behavior. In the present study, self efficacy mediated the relationship between perceived benefits/barriers to condom use and safer sex intentions. Perceived positive and negative consequences of engaging in safer sex practices seems to influence African-American gay/bisexual men's self-confidence for exercising such behavior, which in turn influences their intention to practice safer sex. These results are consistent with previous findings that selfefficacy is a potent predictor of safer sex (e.g., Flowers et al., 1997; Sheeran et al., 1999). Although researchers have not typically viewed self efficacy as a mediator in the HBM (see Rosenstock et al., 1988), original theoretical formulations of this construct describe self-efficacy as a mediating variable (e.g., Bandura, 1986); and the findings in this study match prior research in which self-efficacy operated as a mediator (Wulfert \& Wan, 1993). Safer sex campaigns for American-American gay/bisexual men should focus on increasing their confidence to use condoms and practice safer sex. Although addressing perceived benefits and barriers to safer sex practices can help increase self-efficacy, increasing gay socialization can also accomplish this by helping men feel comfortable with their sexuality, accepted by others, and connected to and supported by peers-opening the door to personally integrating values and following practices that are consistent with sexual health.

Finally, a distinction must be made between the theoretical, statistical, and practical significance of variables that are hypothesized to influence safer sex practices. Although factors like acculturation and gay socialization were not statistically significant at the .o1 level in all of the analyses for the current study, there are clear conceptual reasons why these variables are believed to influence safer sex behavior. Safer sex interventions must be com- 
prehensive. Thus, variables that are not statistically significant should not be automatically ignored; such variables may well have great theoretical and practical significance in promoting safer sex behavior.

\section{Clinical Implications and Conclusions}

The findings of this study may be limited by the cross-sectional design with self-reported data, demand characteristics, and the artificial nature of the research setting. Social desirability and the financial incentive may have influenced responses and participation in the study. The sample comes from one city in the United States, which limits the external validity of the results. Inferences about causation cannot be made.

Nonetheless, this study provides important information about the HBM and HIV prevention in a high risk, minority population. The results suggest that African-American gay/bisexual men face several challenges when they attempt to maintain their sexual health. Not only do these men need to possess positive condom attitudes and perceive few partner barriers to safer sex, but they may also need to maintain a level of comfort with their sexuality. Sexual self-acceptance may allow an African-American gay/bisexual man to think more freely and explicitly about the potential consequences of unprotected sexual activity. Having a sense of connection with other gay/bisexual men who make safer sex a priority can provide motivation, support, and reinforcement for consistent safer sex practices.

Public health professionals can use the results of this study to create effective safer sex interventions that target the African-American gay/bisexual male community. Modified forms of the Health Belief Model can serve as a basis for these efforts. Intervention strategies should promote positive safer sex attitudes, favorable social norm perceptions of safer sex, and high levels of self-efficacy among African-American gay/bisexual men. Safer sex strategies (e.g., safer sex advertisements, free condoms, pamphlets about safer sex behavior) could be promoted in magazines, newspapers, bars, bookstores, and community events that receive heavy patronage from gay/bisexual men-particularly African-American gay/bisexual men. Community health centers could hold safer sex workshops for African-American gay/bisexual men where sexual assertiveness skills could be taught and rehearsed to increase their sense of self-efficacy (e.g., see Kalichman et al., 1996). Community agencies could also sponsor recreational and social support activities among African-American gay/bisexual men where safer sex behavior is a recurring theme. These activities would promote a sense of group cohe- 
sion - a sense of community that would bolster gay socialization and enable African-American gay/bisexual men to enhance their psychological wellbeing as well as their sexual health (Frost \& Meyer, 2012).

Brian D. Zamboni's research focuses on sexual health, sex education, and marginalized populations.

Isiaah Crawford's research has focused on HIV prevention, minorities and marginalized populations.

Fred B. Bryant's research has focused on quality of life, savoring, and test validity. He is an expert in the use of structural equation modeling and advanced statistical techniques.

\section{References}

Agronick, G., O’donnell, L., Stueve, A., San Doval, A. Duran, R., \& Vargo, S. (2004) Sexual behaviors and risks among bisexually- and gay-identified young Latino men. AIDS Behavior, 8, 185-197.

Albarracin, D., Gillette, J. C., Earl, A. N., Glasman, L. R., Durantini, M. R., \& Ho, M. H. (2005). A test of major assumptions about behavior change: A comprehensive look at the effects of passive and active HIV-Prevention interventions since the beginning of the epidemic. Psychological Bulletin, 131, 856-897.

Albarracin, D., Johnson, B. T., Fishbein, M., \& Muellerleile, P. A. (2001). Theories of reasoned action and planned behavior as models of condom use: A meta-analysis. Psychological Bulletin, 127, 142-161.

Aronson, R. E., Rulison, K. L., Graham, L. K., Pulliam, R. M., McGee, Warner, L., Labban, J. D., Dingman, D., \& Rhodes, S. D. (2013). Brothers leading health lives: Outcomes from the pilot testing of a culturally and contextually congruent HIV prevention intervention for Balck male college students. AIDS Education and Prevention, 25, 376-393.

Aspinwall, L. G., Kemeny, M. E., Taylor, S. E., Schneider, S. G., \& Dudley, J. P. (1991). Psychosocial predictors of gay men's AIDS risk-reduction behavior. Health Psycholo$g y, 10,432-444$.

Bakker, A. B., Buunk, B. P., Siero, F. W., Van Den Eijnden, R. J. J. M. (1997). Application of a modified health belief model to HIV preventive behavioral intentions among gay and bisexual men. Psychology and Health, 12, 481-492.

Bandura, A. (1986). Social foundations of thought and action: A social cognitive theory. Englewood Cliffs, NJ: Prentice Hall.

Boone, T. L., \& Lefkowitz, E. S. (2004). Safer Sex and the Health Belief Model: Considering the Contributions of Peer Norms and Socialization Factors. Journal of Psychology \& Human Sexuality, 16(1), 51-68.

Brien, T. M., Thombs, D. L., Mahoney, C. A., \& Wallnau, L. (1994). Dimensions of self Efficacy among three distinct groups of condom users. Journal of American College Health, 42,167-174. 
Brunswick, A. F. \& Banaszak-Holl, J. (1996). HIV risk behavior and the health belief model: An empirical test in an African American community sample. Journal of Community Psychology, 24, 44-65.

Carpenter, C. J. (2010). A meta-analysis of the effectiveness of health belief model variables in predicting behavior. Health Communication, 25(8), 661-669.

Casey, M. K., Timmermann, L., Allen, M., Krahn, S., \& Turkiewicz, K. L. (2009). Response and self-efficacy of condom use: A meta-analysis of this important element of AIDS education and prevention. Southern Communication Journal, 74(1), 57-78.

Centers for Disease Control and Prevention. (2015). HIV Surveillance Report, 2014; vol. 26. http://www.cdc.gov/hiv/library/reports/surveillance/Published November 2015

Crawford, I., Allison, K., Zamboni, B. D., \& Soto, T. (2002). The influence of dual identity development on the psychosocial functioning of African-American gay and bisexual men. Journal of Sex Research, 39, 179-189.

Cuellar, I., Nyberg, B., Maldonado, R. E., \& Roberts, R. E. (1997). Ethnic identity and acculturation in a young adult Mexican-origin population. Journal of Community Psychology, 25, 535-549.

David, S. \& Knight, B. G. (2008). Stress and coping among gay men: Age and ethnic differences. Psychology and Aging, 23, 62-69.

DeHart, D. D., \& Birkimer, J. C. (1997). Trying to practice safer sex: development of the sexual risks scale. Journal of Sex Research, 34, 11-25.

Flowers, P., Sheeran, P., Beail, N., \& Smith, J. A. (1997). The role of psychosocial factors in HIV risk reduction among gay and bisexual men: A quantitative review. Psychology and Health, 12, 197-230.

Ford, K. \& Norris, A. E. (1995). Factors related to condom use with casual partners among urban African-American and Hispanic males. AIDS Education and Prevention, 7, 494-503.

Frost, D. M., \& Meyer, I. H. (2012). Measuring community connectedness among diverse sexual minority populations. The Journal of Sex Research, 49, 36-49.

Gerrard, M., Gibbons, F. X., \& Bushman, B. J. (1996). Relation between perceived vulnerability to HIV and precautionary sexual behavior. Psychological Bulletin, 119, 390-409.

Helweg-Larsen, M. \& Collins, B. E. (1994). The UCLA multidimensional condom attitudes scale: Documenting the complex determinants of condom use in college students. Health Psychology, 13, 224-237.

Hergenrather, K. C., Emmanuel, D., Durant, S., \& Rhodes, S. D. (2016). Enhancing HIV prevention among young men who have sex with men: A systematic review of HIV behavioral interventions for young gay and bisexual men. AIDS Education and Prevention, 28(3), 252-271.

Holmbeck, G. N. (1997). Toward terminological, conceptual, and statistical clarity in the study of mediators and moderators: Examples from the child-clinical and pediatric psychology literatures. Journal of Consulting \& Clinical Psychology, 65, 599-610.

Joreskog, K. G., \& Sorbom, D. (1996). LISREL 8: User's reference guide. Chicago, IL: Scientific Software International. 
Kalichman, S. C., Rompa, D., \& Coley, B. (1996). Experimental component analysis of a behavioral HIV-AIDS prevention intervention for inner-city women. Journal of Consulting and Clinical Psychology, 64, 687-693.

Khalil, S. N., Ross, M. W., Rabia, M., \& Hira, S. (2005). Knowledge and Attitudes Towards HIV/STD Among Indian Adolescents. International Journal of Adolescence and Youth, 12(1-2), 149-168.

Kline, R. B. (1998). Principles and practice of structural equation modeling. New York: The Guilford Press.

Lacefield, K., Negy, C., Schrader, R. M., \& Kuhlman, C. (2015). Comparing psychosocial correlates of condomless anal sex in HIV-diagnosed and HIV-nondiagnosed men who have sex with men: A series of meta-analyses of studies from 1993-2013. LGBT Health, 2(3), pp. 200-220.

Landrine, H., \& Klonoff, E. A. (1994). The African-American acculturation scale: Development, reliability, and validity. Journal of Black Psychology, 20, 104-127.

Lewis, J. E., Malow, R. M., Ireland, S. J. (1997). HIV/AIDS risk in heterosexual college students: A review of a decade of literature. Journal of American College Health, 45, 147-158.

Mahoney, C. A. (1995). The role of cues, self-efficacy, level of worry, and high-risk behaviors in college student condom use. Journal of Sex Education and Therapy, 21, 103-116.

Meyer, I. H. (2010). Identity, stress, and resilience in lesbians, gay men, and bisexuals of color. The Counseling Psychologist, 38, 442-454.

Neff, J. A. \& Crawford, S. L. (1998). The health belief model and HIV risk behaviours: A causal model analysis among Anglos, African-Americans, and Mexican-Americans. Ethnicity and Health, 3, 283-299.

O’Leary, A., Fisher, H. H., Purcell, D. W., Spikes, P. S., \& Gomez, C. A. (2007). Correlates of risk patterns and race/ethnicity among HIV-positive men who have sex with men. AIDS and Behavior, 11(5), 706-715.

Phinney, J. S. (1992). The multigroup ethnic identity measure: A new scale for use with diverse groups. Journal of Adolescent Research, 7, 156-176.

Ratti R., Bakeman, R. \& Peterson, J. L. (2000). Correlates of high-risk sexual behaviour among Canadian men of South Asian and European origin who have sex with men. AIDS Care, 12, 193-202.

Rosenstock, I. M. (1974). Historical origins of the health belief model. Health Education Monographs, 2, 328-335.

Rosenstock, I. M., Strecher, V. J., \& Becker, M. H. (1988). Social learning theory and the health belief model. Health Education Quarterly, 15, 175-183.

Sacco, W. P., Levine, B., Reed, D. L., \& Thompson, K. (1991). Attitudes about condom use as an AIDS-relevant behavior: Their factor structure and relation to condom use. Psychological Assessment, 3, 265-272.

San Doval, A., Duran, R., O’Donnell, L., \& O’Donnell, C. R. (1995). Barriers to condom use in primary and nonprimary relationships among Hispanic STD clinic patients. Hispanic Journal of Behavioral Sciences, 17, 385-397. 
Seibt, A. C., Ross, M. W., Freeman, A., Krepcho, M., Hedrich, A., McAlister, A., \& Fernandez Esquer, M. E. (1995). Relationship between safe sex and acculturation into the gay subculture. AIDS Care, 7, S85-S88.

Sheeran, P., Abraham, C., \& Orbell, S. (1999). Psychosocial correlates of heterosexual condom use: A meta-analysis. Psychological Bulletin, 125, 90-132.

St. Lawrence, J. S., Chapdelaine, A. P., Devieux, J. G., O’Bannon, R. E., Brasfield, T. L., \& Eldridge, G. D. (1999). Measuring perceived barriers to condom use: Psychometric evaluation of the condom barriers scale. Assessment, 6, 391-404.

Stokes, J. P., Vanable, P. A., McKirnan, D. J. (1996). Ethnic differences in sexual behavior, condom use, and psychosocial variables among black and white men who have sex with men. Journal of Sex Research, 33, 373-381.

Strahan, R., \& Gerbasi, K. C. (1972). Short, homogenous versions of the MarloweCrowne social desirability scale. Journal of Clinical Psychology, 28, 191-193.

Strecher, V. J., Champion, V. L., \& Rosenstock, I. M. (1997). The health belief model and health behavior. In D. S. Gochman (Ed.), Handbook of health behavior research I: Personal and social determinants (pp. 71-91). New York: Plenum Press.

Tanaka, J. S. (1993). Multifaceted conceptions of fit in structural equation models. In K. A. Bollen \& J. S. Long (Eds.), Testing structural equation models (pp.10-39). Newbury Park, CA: Sage Publications, Inc.

Vanable, P. A., McKirnan, D. J., \& Stokes, J. P. (1998). Identification and involvement with the gay community scale. In C. M. David, W. L. Yarber, R. Bauserman, G. Schreer, \& S. L. Davis (Eds.), Handbook of sexuality-related measures (pp. 407-409). Thousand Oaks, CA: Sage Publications.

Wulfert, E. \& Wan, C. K. (1993). Condom use: A self-efficacy model. Health Psychology, $12,346-353$.

Wulfert, E., Wan, C. K., \& Backus, C. A. (1996). Gay men's safer sex behavior: An integration of three models. Journal of Behavioral Medicine, 19, 345-366.

Zagumny, M. J., \& Brady, D. B. (1998). Development of the AIDS health belief scale (AHBS). AIDS Education and Prevention, 10, 173-179. 